\title{
THE SOVIET ATTITUDE TO STRESS IN BATTLE C DONNELLY
}

\author{
Reader in Soviet Studies, Royal Military Academy, Sandhurst
}

The Soviet attitude to battlefield stress in characterised by:

a. a widespread recognition of the causes and effects of stress on the individual and the threat this poses to the viability of the unit in combat;

b. a realisation of the value of exploiting the effects of stress on the enemy;

c. a serious study of all aspects of the Soviet military system designed to identify points where the individual and the system are particularly vulnerable;

d. a coordinated and sustained effort to get incorporated into training and tactics:

(i) Such measures as would serve to increase their own vulnerability, and

(ii) such measures as would increase to critical levels the stress imposed on the enemy at crucial point and times in the battle.

The key to the understanding of the Soviet military system is an appreciation of the function and importance of Soviet Military Doctrine.

There is no equivalent in the British Army of such a military doctrine. We pride ourselves in inculcating initiative in our officers and soldiers, on the level of independence of action allowed to commanders at all levels. We tend to assume that a military doctrine stifles initiative, destroys independence of thought (and therefore of activity) and leads to stereotyped action. Whilst even the Russians would agree that there is an element of truth in this assessment, it is a far from fair definition of their concept of a Military Doctrine in which they have such pride and on which they rely so heavily. On the other hand, the Russians often deride our 'reliance on native wit' (which is how they translate our concept of initiative), considering it to be a poor substitute for a carefully worked out and detailed plan.

The Soviets see their Military Doctrine as the accumulated wisdom and experience of generations of competent Soviet soldiers. This body of knowledge is constantly being amended by experimentation, exercises and a thorough and meticulous academic and practical study of past wars. It is impossible not to be impressed by the volume and quality of detailed Soviet analyses of the problems of the battlefield. These analyses and debates, which regularly appear in the open Soviet press, represent a sustained effort to keep Soviet Military Doctrine up to date in all its strategic and tactical aspects.

The upbringing and training of the Soviet soldier and officer, their battle tactics, organisation and equipment, weapons design and procurement, even relations between the Army and the Communist Party and Soviet Society, all these aspects of the Soviet military system are moulded by Soviet Military Doctrine. The result is a military system which is characterised by:

a. an enormous degree of integration and coordination between all its constituent elements; 
b. total consistency between all its elements as regards goals and objectives of the system and means of implementing plans;

c. a widespread awareness of the interdependence and inter-reaction of all elements of the system;

d. a widespread conviction in the value of the system and in its ideological correctness, coupled with a pragmatic approach to the search for solutions to problems of the battlefield.

Their research is not above criticism. It is still hampered by an excess of ideological orientation and a fear of over-frank admissions of failure, and their most serious research concentrates almost to exclusion on their own experience, which is of warfare of a particular scale and style.

However, within these limitations, the Russians have studied and analysed battle from all aspects and their conclusions as to the effect of stress on soldiers in battle (and hence on the military system as a whole) have, as a consequence of their military doctrine, penetrated to all elements of the military organism.

The result is a real awareness of the threat which stress poses to the functioning of the military machine. Under stress, a soldier's ability to perform his military function is reduced. In extreme cases, the Russians maintain, he will be completely unable to perform his military function, indeed to take any coordinated or purposeful action, even though he may be physically uninjured.

Surprise, fear, fatigue and pain are seen as the main components of a stressful situation. When these produce an excess of stress in a short space of time, the individual (and, in the Soviet view, the organization as well) is subject to shock $^{*}$, and his will to resist is paralysed. He will fail to perform his military function, and if the system depends on him, then the system will itself fail to function at that point. The effect on the Army may be such that it is unable to make an effective response to the enemy threat.

\section{The imposing of stress on the enemy}

To produce this 'battlefield paralysis of the will' in the enemy is the prime goal of the Soviet commander planning the operation. Consequently, Soviet tactical and operationl doctrine has, as its first three principles, speed of manoeuvre, concentration of effort, and surprise. The aim of the Commander is not to grind away the defenders' strength, but to deliver such a shock to his military system by surprise and weight of blow, followed by a rapid advance deep into his rear, that the defender is paralysed and unable to react. The defence, thus totally and suddenly undermined and de-stabilised at the very outset of the war will therefore collapse quickly, even though a great many troops and units will still be individually viable. Shock, in other words, is to be used to incapacitate the enemy's military system just as shock can incapacitate an individual.

To this end the Soviets hold that it is far better to achieve a surprise attack with minimum forces than to aim for a massive build up which allows the enemy

\footnotetext{
* The Soviet military term for shock is the same as their medical term for apoplectic stroke or heart attack
} 
to steel himself for the onslaught, even though by taking the latter course, the Soviets might ensure a greater degree of numerical superiority. The surprise and momentum will overwhelm the enemy staff system, which will be unable to cope with the volume of information it will receive in a very short space of time. It will consequently be unable to form a viable plan and produce an effective reaction. To compound this effect the Soviets say, it is most important to deliver attacks simultaneously throughout the depths of the enemy position** so as to increase the level of surprise and confusion and consequently the instability of the whole.

This offensive against the defender's rear, and particularly against headquarters, command and control elements in the rear will take three forms:

(i) physical attack, by bomb or sabotage squad; (ii) electronic attack; (iii) rumour and psychological attack.

The aim of the physical attack is

a. to create physical destruction of the command system so as to reduce the ability of the defenders' military system to react, and

b. to create fear amongst the staff for their own personal safety, thus increasing the burden of stress upon them.

The aim of the electronic attack is

a. to prevent communication and further hinder reaction; and

b. to create frustration and a sense of impotence amongst the staff, further heightening the pressures on them and reducing their confidence and hence their resistance to stress.

\section{By rumour and psychological attack}

a. spread before the war to sap the defenders' confidence in their ability to win; and

b. spread during the war to heighten fear.

The mental resilience of the defender may be reduced still further by the creation of uncertainty and lack of confidence.

Yet another Soviet principle of tactical and operational doctrine stresses the need to maintain continued pressure on the defender. This will deny the enemy time to rest and recover and will create extreme fatigue. Fatigue is held to be a most important physical contribution to reducing resistence to stress.

As a practical way to achieve surprise and shock at the tactical level, the Soviets stress the use of new weapons and tactics. The enemy's resistance to stress will be weakened by encounters with the unexpected. Flame throwers and smoke screens are given as tactical weapons producing a high shock effect. Chemical weapons are particularly valued because of the fear that even rumours of their use will inspire. Nuclear weapons, however, both of the high-blast type and of the enhanced radiation type, create by far the biggest shock to the system

** This is actually another principle of Soviet tactical and operational doctrine. 
due both to their extreme destructiveness and the fear the threat of their residual effect creates amongst the men.

In terms of planning the use of conventional weapons, this 'shock' effect to the defender is held as being just as important, and in some cases even more important than any physical destruction which that use might accomplish. Thus in the realm of artillery fire planning, fire in support of the attack must be planned so as to achieve not so much maximum casualties as maximum shock. The heaviest

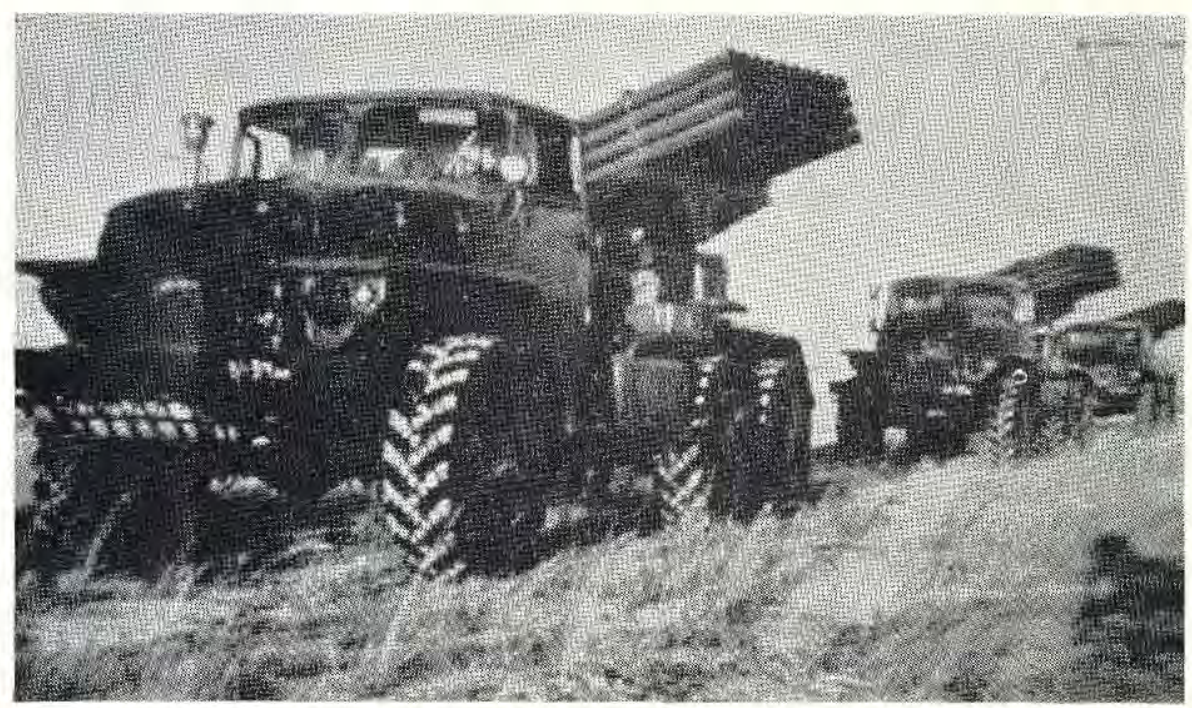

Fig. 1. The multi-barrelled rocket launcher, or "Stalin Organ," is regarded by the Soviets as a psychological weapon to shock, paralyze, daze and stupefy rather than kill or injure. One battery can deliver 720 rounds of $122 \mathrm{~mm}$ calibre in 30 seconds.

barrage practicable in modern war would, the Russians say, incapacitate some $25 \%$ of defenders and equipment if these were properly entrenched. What matters, however, is not that the subsequent Soviet offensive would only be met by fire from $75 \%$ of defenders surviving - the number who ultimately die or are hospitalised is virtually irrelevant - what matters is that for a certain time after the barrage ceases, none of the defenders should be capable of firing their weapons at the attackers, including those not actually injured. The shock of the heavy shelling will paralyse and stupefy them, and they will be sitting in a daze in their trenches when the first Soviet infantry arrive. The Russians have always valued the multi-barrelled rocket launcher for just this reason: its massive volume of fire (in the last war usually used to end a bombardment) has as its main advantage the shock it delivers to the enemy troops, rather that the lethality of its warhead.*

* For an example of a study taking this factor into account, see 'Voennig vestnik', 1980 No 4 p 64. This article, drawing on Soviet tactical exercises and analyses of the Arab-Israel war of 1973 concludes, inter alia, that the success of a (continued overleaf) 


\section{Reducing the effect of stress on Soviet forces}

The tactics of the Soviet Army are designed to give the system a high degree of resistance to stress. Tactics are very well thought out and extremely simple, and everything is reduced to basic drills. These drills do not demand of the soldier a high degree of mental toil. If they are well learned, then to a certain extent they can be performed automatically. The first casualty of stress, the Russians maintain, will be clear and reasoned thinking. The last thing to go from a soldier's mind, will be well rehearsed drills. It is here that drill and repetition score over intellect, wit and initiative.

This realization certainly militates against the deployment of complex weaponry. If advanced technology is used, the Russians insist that it must serve to simplify the soldier's task and not to make it more complicated and therefore more wearing. In the area of highest technology on the battlefield--the jet plane - the application of this policy is very clear. Firstly, Soviet pilots have much less scope for initiative, and are directed on to their targets to a much greater extent than is the case in NATO Air Forces. Secondly, pilot training aims at the creation of a 'dynamic stereotype in the cerebral cortex'; ie the training is geared to producing complex reflex actions which do not depend on intellectual effort but which will be performed semi-automatically in the high-stress situation of the cockpit of a plane under attack.

A similar approach is taken towards the training of all-arms commanders. A Soviet ground forces commander is taught that the offensive can be carried out in one of a certain number of ways. Consequently, when he is preparing for battle, he does not make a plan but, in Soviet terms, he makes a decision; ie he decides which of his pre-learned alternatives to employ, then he amends his choice to suit particular circumstances.

This makes his actions much more automatic and therefore less demanding and more capable of being performed quickly and efficiently under stress. This method of operation is made even more automatic by teaching the commander to lay' out his operational problems as 'flow charts' or algorithms, to help him come to a quick decision. The Russians are far from confident that they have solved the problem of information handling, decision making and planning, however they are tackling this as a matter of priority.

Tactically, of course, the Soviet Army tries like any other army to ensure that it will not be surprised. The Russians recognise that one of their greatest vulnerabilities is to being surprised, and they take great pains to make very detailed plans, based on the conviction that it is only by achieving surprise themselves,

* high speed attack depends on the total temporary loss of combat effectiveness by the enemy. The author lays particular emphasis on choosing methods of artillery support which take the psychological factors into consideration. He gives the following times of recovery for defenders, in trenches, 5-10 metres from their weapons, subjected to accurate bombardment for six minutes: Machine-guns 45 seconds, ATGWs (Milan type) 60-70 seconds, Anti Tank gun 2-3 minutes, Tank 2-3 minutes. That is, the length of the time it will take them from the last Soviet round falling until they can open fire. 
and by exploiting it very quickly indeed, that the enemy can be kept off balance and prevented from delivering a counter blow (for which the Russians have been unable to preplan). Achieving surprise is, therefore, one of the surest ways to avoid being surprised. Likewise the value of early success is noted by the Russians, as contributing to confidence building and the creation of a strong morale which will reinforce the psyche and enable it to bear stressful situations more effectively.

One good example of such tactics being particularly tailored to reduce exposure to stress can be seen in the Soviet organisation of the march. In this concept, the Russians view it as essential that, when moving troops over long distances into combat: firstly, they must be protected against surprise attack by a security screen maintained around the marching column at all times; secondly, the march must be broken by substantial rest periods and the men must be given chance to sleep. Deprivation of sleep for long periods is, in Soviet eyes, one of the most serious factors contributing to a decline in resistance to stress.

Moral conditioning of the man is another important bulwark against stress. The Russian language has no word for privacy. Morale is collectively generated and best maintained by group interaction. Loyalty to the collective and the creation of teams is seen as essential to sub unit cohesion on the battlefield. Tactics are therefore employed which attempt to improve cohesive action and avoid sub unit isolation. Street fighting and fighting in broken and hilly country are seen by the Soviets as very great threats to the viability of units because they force the deployment of minor sub units in isolation which the Russian mentality is, they say, ill equipped to cope with. Concern for this sensitivity to isolation is shown by recent restoration of the need for infantrymen in defence to dig two-man instead of individual foxholes for mutual psychological comfort and support. It is not just the Soviet soldier who relies on the support of his fellows for his ability to continue to fight, but perhaps this is even more important for Ivan than it is for his British counterpart.

Inherent in Marxist ideology is the conviction that everything is explicable in human terms. The Russians are emotionally very volatile, and prone to go from elation to despair very quickly. Resistance to stress, in terms of level of morale, can alter very quickly indeed and thus create a high level of unpredictability as to how well the soldier will cope with, say, a reverse on the battlefield. Recently, the Soviets have invested a lot of effort in the study of biorhythms in an attempt to predict individual cycles of depression and elation. This is held to make the individual more aware of the changing nature of his moods and therefore more resilient to these changes of mood because he will recognise them for what they are.

Preparing the soldier for the horrors of the battlefield, the sight of death, the effect of fear on his own body, and particularly the noise, is seen by the Russians as being an essential part of psychological hardening. Without a real effort to prepare the man for what he will experience, Soviet authors insist, the shock of battle will make the soldier not wish to go on.

'Frequently in the last war' said the then head of Soviet combat training Gen Salmanov in a recent article, 'the attack halted because at critical moments of the battle attempts to overcome fear amongst the men failed.' Certainly, in the last war, one of the most effective means of overcoming this fear and forcing the Russian soldier on was a draconian system of discipline. The Russian is by nature amenable to 
coercion. Force has always been a very effective means of rule in the country, and force has always been the single most important element in the army's disciplinary system. Examples abound in all armies of officers keeping their men in the line by brute force. In the Soviet Army this is legalised and formalised. Execution of a soldier on the battlefield was a matter of company punishment during the last war. It may seem surprising to maintain that the application of force and the creation thereby of fear can be used effectively to overcome fear from other causes, yet in the ultimate, that is what the Russians do say. By no means does their disciplinary system rely on this alone. There is an intense effort to inculcate in the individual moral self righteousness and conviction in the cause. There is also a determined effort to inculcate in the soldier a fierce hatred of the enemy and a belief in the threat that the enemy presents. Backing this up, however, is a heritage of rule by coercion, and a history of wars fought by means of coercion applied on the soldier, which the Russian is fully aware of.

It is in this sphere that the role of the company political officer is of paramount importance in the Soviet system. He it is who, in every army company, has the task of conducting agitation and propaganda, indoctrinating the Soviet soldier, teaching him why he has to fight, teaching him to hate his enemy, and inculcating in the soldier those qualities of bravery and self sacrifice which the system deems desirable It is also the political officer who, however, must use his authority to enforce discipline, and who must mobilise the emotions of the sub unit so as to apply support and pressure to the individual so as to prevent his morale from 'cracking.' The Soviet system is a 'driven' system, not a self-motivated one. This must not be read as a criticism of the Soviet system nor must it be dismissed on moral considerations. In terms of pure practicality, the Russian reacts positively to being driven. There is increasing evidence that the Soviet soldier of today, more sophisticated than ever before, may not be so amenable to this style of discipline in a future war as he was in past wars. Nevertheless there can be no doubt that, whilst the Soviet system might change in the future, even the near future, it has not changed radically yet. If a major war were to occur in Europe tomorrow, coercion would still be a major feature of dicipline on the battlefield for the Soviet soldier.

There is nothing new in what we have said above. There is no one single feature of the Soviet attitude to the stress of battle and its effect on man and the military machine that can be called revolutionary, or even that is unique to the Soviet Army. What makes for a special Soviet approach is the combination of attitudes; the recognition of the problem and a conscious effort to deal with it. 